\title{
Acceptor/Donor End Capped Phenylene-Thiophene Co-oligomers Toward Efficiencies Organic Electronic Devices
}

\author{
Abdelkader Hlel ${ }^{1,}$, Saber Ghomrasni ${ }^{2}$, Walid Taouali ${ }^{2}$, Kamel Alimi ${ }^{2}$ \\ ${ }^{1}$ Department of Physics, Preparatory Institute for Engineering Studies, University of Monastir, Monastir, Tunisia \\ ${ }^{2}$ Department of Physics, Faculty of Sciences, University of Monastir, Monastir, Tunisia
}

Email address:

kaderhlel@yahoo.fr(A.Hlel), ghomrasnis@yahoo.fr (S. Ghomrasnni), tawali_walid@yahoo.fr(W. Taouali),

kamel.alimi@fsm.rnu.tn (K. Alimi)

${ }^{*}$ Corresponding author

\section{To cite this article:}

Abdelkader Hlel, Saber Ghomrasni, Walid Taouali, Kamel Alimi. Acceptor/Donor End Capped Phenylene-Thiophene Co-oligomers Toward Efficiencies Organic Electronic Devices. International Journal of Computational and Theoretical Chemistry.

Vol. 8, No. 1, 2020, pp. 1-10. doi: 10.11648/j.ijctc.20200801.11

Received: November 11, 2019; Accepted: December 3, 2019; Published: January 4, 2020

\begin{abstract}
In this paper, geometrical (in ground and excited states), electronic, optical and charge transfer properties, (ionization potentials (IP), electron affinities (EA) and HOMO-LUMO gaps $\left(\Delta \mathrm{E}_{\mathrm{H}-\mathrm{L}}\right)$, as well as the lowest excitation energies $\left(E_{e x}\right)$ and reorganization energies) of the phenylene-tiophene oligomers are studied by the density functional theory (DFT) and Time-dependent DFT approaches. Based on the density functional theory (DFT/B3LYP and CAM -B3LYP functional with 6$31 \mathrm{G}(\mathrm{d}, \mathrm{p})$ basis set), we will highlight the effect of terminal acceptor/donor $\left(\mathrm{CN}, \mathrm{NO}_{2}\right.$, and $\left.\mathrm{CF}_{3}\right) / \mathrm{OCH}_{3}, \mathrm{~N}\left(\mathrm{CH}_{3}\right)_{2}$ substituents on thiophene-phenylene derivatives. The excited state indicates more planar structures of the co-oligomers, which leads to a decrease in the (HOMO-LUMO) gap compared with the ground state, especially when the acceptor character increases. Furthermore, the vinyl spacer and cyanide $\left((-\mathrm{CN})\right.$ functional group $\left(\right.$ Compound $\left.\mathrm{C}_{8}\right)$ stabilize the LUMO levels of energy and improve the transport properties of the thiophene-phenylene derivatives. Comparing with the donor groups, the results show that the electron withdrawing substituents are remarkable on the energy levels of the frontier molecular orbitals, and on the transport charge proprieties in these co-oligomers. Thus, the LUMO energy levels become more stabilized for co-oligomers having more acceptor moieties and the HOMO-LUMO energy gap is reduced, therefore, the improvement of the conduction properties of these species is, then, observed. Moreover, the absorption spectra, computed in the presence or not of solvent at PCM model in chloroform, shows that the increase of acceptor character induces a red shift and important absorption intensity. The decrease injection barrier and smaller reorganization energies are revealing that our designed co-oligomers would be an efficient hole as well as electron transfer materials. The predicted values have shown that the designed derivatives would be efficient for the organic field effect transistors, photovoltaics and light emitters.
\end{abstract}

Keywords: Thiophene-phenylene, DFT, CAM-B3LYP, B3LYP, Optical Absorption, Reorganization Energies

\section{Introduction}

The oligothiophene-phenylene is considered among the most important semi organic conductors [1, 43, 44]. Indeed their hybridization is a highly desired outcome to expect the benefit properties of this coupling. A significant number of publications $[2-5,45]$ is focused on these co-oligmers viewing their original and interesting proprieties. These thiophene-phenylene derivates are among the crystalline organic semiconductor, combining both an efficient charge transport, (a charge mobility $\sim 1 \mathrm{~cm}^{2} /(\mathrm{V} \mathrm{s})$ ) and a strong luminescence [6]. The forbidden band (gap) is a means of electrical control properties of organic semiconductor, which is strongly governed by the delocalization of $\pi$-electrons along the conjugated structure. Thiophene-phenylene cooligomers cover a gap ranging from 2.00 to $3.50 \mathrm{eV}$, allowing them a wide operating in opto-electronic devices (OLED, photovoltaic cell, transistors, sensors...) $[7,8,46]$. Several 
recent studies [9-11] have investigated the effect of vinylene units appended to an oligo-thiophene chain on electronic and on the charge transfer properties in order to enhance the performance of organic electronic device.

On the other hand, more researches on electronic organic compound are directed towards the preparation of a performant acceptors/donors and transporter materials of electron/hole [12-16]. Consequently, we try to illumine the relationships between the structure and the electronic properties of these co-oligomers as appears in Figure 1.

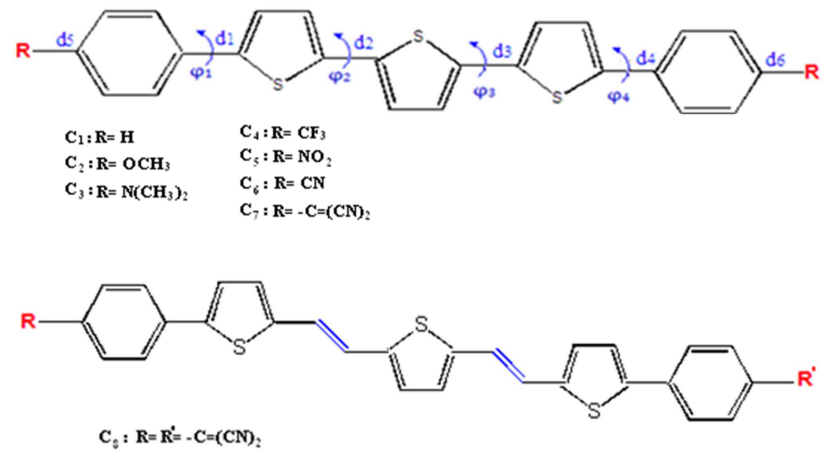

Figure 1. Chemical structures of all compounds.

In fact, in this paper we study the effect of different electron-withdrawing groups $\left(-\mathrm{CF}_{3},-\mathrm{CN},-\mathrm{NO}_{2}\right)$ and donor groups $\left(\mathrm{OCH}_{3}, \mathrm{~N}\left(\mathrm{CH}_{3}\right)_{2}\right)$ attached to both extremities of cooligomer thiophene-phenylene. Firstly, the fact that the incorporation of electron withdrawing substituents decreases the LUMO energies levels, which facilates the electron injection and also improves the solubility of compound [17]. Secondly, according to the work of Newman et al. the compounds with electronic affinity $(3.0-4.0 \mathrm{eV})$ are considered as good n-type devices for OFETs owing to the efficient electron injection from common gold electrode, and enough ambient stability [18]. Thirdly, the functionalization with donor groups can also enhance the hole injection and solubility.

The substituents allow a shift of the frontier molecular orbital energies that are the key to achieving the electron or hole charge transport. To argue our conclusion based on DFT we compare our theoretical calculations with available experimental observations [19, 3, 45]. We use B3LYP and CAM-B3LYP in both gas and solvent phase to study the electronic transitions of these compounds.

\section{Computational Details}

All calculations are performed using the Gaussian 09 program package [20]. The geometric optimization of these thiophene-phenylene co-oligomers is carried out at DFT [21, 22] level using the 6-31G(d,p) basis set [23, 47]. The Becke's three parameter gradient-corrected exchange potential and the Lee-Yang-Parr gradient-corrected correlation potential (B3LYP) [24-26] and Coulomb Attenuating Method (CAMB3LYP) [27] has been used for all the calculations.

The absorption spectra are carried out using the time- dependent density functional theory [28, 29]. In this study TD-DFT methods with the CAM-B3LYP, B3LYP functionals are used to compute the UV/Vis spectra. The solvent effect on the geometric optimization and the transition energies are considered using the polarized continuum model (PCM) of the self-consistent reaction field (SCRF) theory $[30,31]$. The equilibrium structure of the first singlet excited states (S1) has been optimized using the restricted CIS (RCIS) theoretical method with the 6-31G $(d, p)$ basis set [32]. Moreover, the obtained data are transformed using the Swizard program [33] into simulated spectra as described in literature [34].

Finally, to evaluate the reorganization energy of all the cooligomers, the cationic and anionic geometry are fully optimized by B3LYP / 6-31G (d,p) method and compared to that of the ground state.

\section{Results and Discussion}

\subsection{Ground and Excited States Geometry}

The DFT/B3LYP/6-31G (d,p)-optimized ground-state geometries of the co-oligomers are shown in Figure 2.

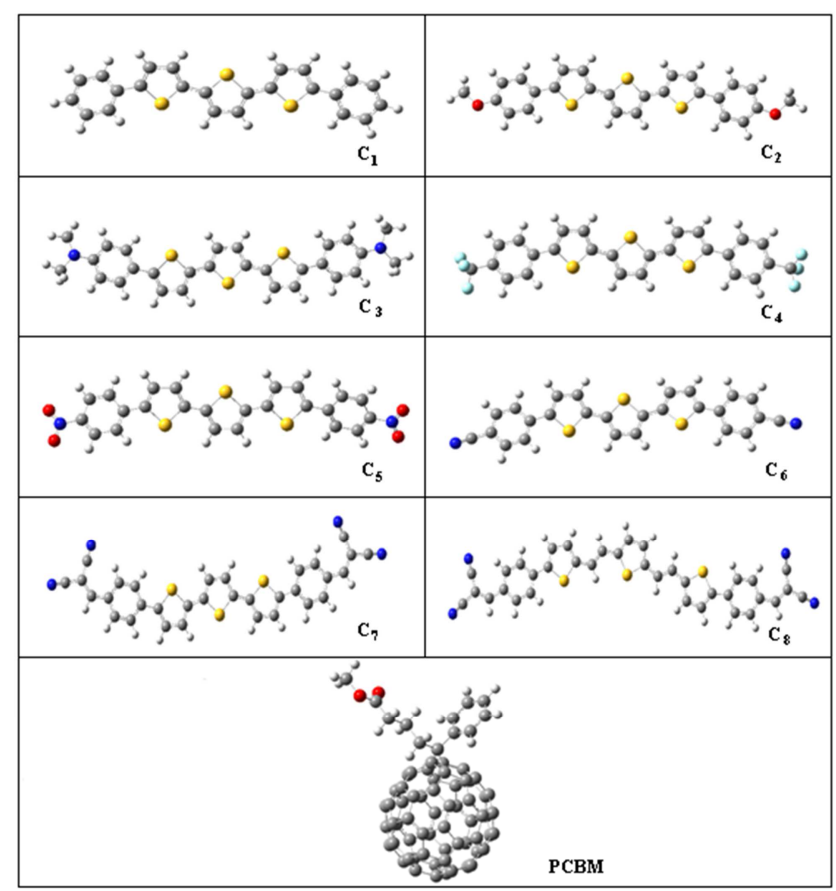

Figure 2. Optimized geometries obtained by B3LYP/6-31G (d, p) of the studied co-oligomers.

In their ground states, dihedral angles $\varphi_{2}$ and $\varphi_{3}$ are similar also $\varphi_{1}$ and $\varphi_{4}$ are the same for all compounds. On the other hand, the dihedral $\varphi_{1}$ angle between the outermost thiophene units and the terminal, para-substituted phenyl groups are, $25.7^{\circ}, 21.9^{\circ}, 23.8^{\circ}, 20.81^{\circ}$ and $16.4^{\circ}$ for $\mathrm{C}_{1}, \mathrm{C}_{2}, \mathrm{C}_{3}, \mathrm{C}_{5}$ and $\mathrm{C}_{7}$, respectively, (we note that $\varphi_{1}=\varphi_{4}$ for all these compounds). Moreover, co-oligomer $\mathrm{C}_{8}$ presents the lower dihedral angle $\varphi_{1}=13.03^{\circ}$, and lower inter-ring bond lengths which leads to the most planar of all structures related to the 
presence of the vinyl groups in its main chain and the cyano groups in its end chain. Thus, the cyano groups slightly induce more planar structures in the para-cyanophenyl ends of the end-capped terthiophene chains. According to table 1 the electron-withdrawing groups induce more planar structures than the electron-donating groups of the thiophenephenylene co-oligomers. So, the electronic delocalization along the chain backbone is improved and, therefore, accompanied with an increase of the conjugation. Furthermore, the increase of the donor $\left(-\mathrm{H}<\mathrm{OCH}_{3}<\mathrm{N}\left(\mathrm{CH}_{3}\right)_{2}\right)$ or the withdrawing $\left(\mathrm{F}<\mathrm{NO}_{2}<\mathrm{CN}\right)$ character enhances the planarity of the co-oligomers, consequently, the (HOMOLUMO) gap decreases.

Table 1. Selected bond lengths (A) and dihedral angle (degree) of ground-and excited state geometries (values in parenthesis) of co-oligmers calculated by $B 3 L Y P / 6-31 G(d, p)$ level of theory.

\begin{tabular}{|c|c|c|c|c|c|}
\hline \multirow{2}{*}{ Oligomers } & \multicolumn{3}{|c|}{ Bond lengths $(\AA)$} & \multicolumn{2}{|c|}{ Dihedral angle (degree) } \\
\hline & $d_{1}=d_{4}$ & $\mathbf{d}_{2}=\mathbf{d}_{3}$ & $d_{5}=d_{6}$ & $\varphi_{1}=\varphi_{4}$ & $\varphi_{2}=\varphi_{3}$ \\
\hline $\mathrm{C}_{1}$ & $1.465(1.581)$ & $1.444(1.400)$ & $1.086(1.075)$ & $25.7(18.05)$ & $-11.7(-0.62)$ \\
\hline $\mathrm{C}_{2}$ & $1.464(1.456)$ & $1.443(1.400)$ & $1.363(1.345)$ & $26.2(17.7)$ & $-13.3(-0.69)$ \\
\hline $\mathrm{C}_{3}$ & $1.461(1.451)$ & $1.443(1.401)$ & $1.387(1.382)$ & $23.7(11.92)$ & $-11.7(-0.56)$ \\
\hline $\mathrm{C}_{4}$ & $1.464(1.456)$ & $1.444(1.400)$ & $1.503(1.500)$ & $23.8(15.5)$ & $-14.9(-0.53)$ \\
\hline $\mathrm{C}_{5}$ & $1.460(1.451)$ & $1.443(1.401)$ & $1.465(1.449)$ & $20.8(10.09)$ & $-12.55(-0.41)$ \\
\hline $\mathrm{C}_{6}$ & $1.461(1.452)$ & $1.443(1.400)$ & $1.432(1.440)$ & $21.9(11.8)$ & $-13.7(-0.47)$ \\
\hline $\mathrm{C}_{8}$ & $1.455(1.450)$ & $1.440(1.414)$ & $1.445(1.453)$ & $13.03(7.81)$ & - \\
\hline
\end{tabular}

In the excited states oligomer $\mathrm{C}_{7}$ is perfectly planar $\left(\varphi_{1}=\right.$ $\left.\varphi_{4}=\varphi_{2}=\varphi_{3} \approx 0^{\circ}\right)$. On the one hand, for $C_{8}$ the dihedral angle between thiophene units and the terminal parasubstituted phenyl is $\varphi_{1}=\varphi_{4}=7.81^{\circ}$. However, $\mathrm{C}_{5}$ and $\mathrm{C}_{6}$ are less planar $\left(\varphi_{1}=\varphi_{4} \approx 11^{\circ}\right)$, while for co-oligomers $C_{1}$, $\mathrm{C}_{2}$ and $\mathrm{C}_{4}$ the dihedral angle is high. On the other hand, it can be observed that the dihedral angle decreases to reach $\varphi_{2}=\varphi_{3} \approx 0^{\circ}$ between the consecutive thiophene units for every co-oligomer. As a result, we find out that the excited co-oligomers almost reached planarity. Moreover, we notice that the inter-ring bond lengths are shortened in the excited state $S_{1}$.

\subsection{Frontier Molecular Orbitals}

The electron-accepting properties and the energy gaps of the derivatives are greatly adjusted by the introduction of the terminal groups $\left(-\mathrm{CF}_{3},-\mathrm{CN},-\mathrm{NO}_{2}\right)$. In particular, for compounds $\left(\mathrm{C}_{4}, \mathrm{C}_{7}, \mathrm{C}_{8}\right.$ and $\left.\mathrm{C}_{5}\right)$, we note that the decrease of the energy level of LUMO which is more significant than HOMO after the functionalization of the oligomer $\mathrm{C}_{1}$ with the electron-withdrawing groups. Moreover, in gaseous ground state, a stabilization of HOMO and LUMO energies levels of structures having terminals acceptor group $\left(-\mathrm{CF}_{3},-\right.$ $\mathrm{CN},-\mathrm{NO}_{2}$ ) is noted from the table 2 .

Table 2. HOMO, LUMO energy level and band gap values of different co-oligomers.

\begin{tabular}{|c|c|c|c|c|c|c|}
\hline \multirow{2}{*}{ Compound } & \multicolumn{3}{|l|}{ Gas state } & \multicolumn{3}{|c|}{ solvated state (chloroform) } \\
\hline & $\operatorname{HOMO}^{(\mathrm{g})}(\mathrm{eV})$ & LUMO $^{(\mathrm{g})}(\mathrm{eV})$ & $\Delta \mathbf{E}^{(\mathrm{g})}(\mathrm{eV})$ & HOMO $^{(\mathrm{s})}(\mathrm{eV})$ & LUMO $^{(\mathrm{s})}(\mathrm{eV})$ & $\Delta \mathbf{E}^{(\mathrm{s})}(\mathrm{eV})$ \\
\hline $\mathrm{C}_{1}$ & -4.95 & -1.87 & 3.08 & -5.03 & -2.01 & 3.01 \\
\hline $\mathrm{C}_{2}$ & -4.74 & -1.71 & 3.02 & -4.87 & -1.90 & 2.96 \\
\hline $\mathrm{C}_{3}$ & -4.40 & -1.51 & 2.88 & -4.54 & -1.80 & 2.74 \\
\hline $\mathrm{C}_{4}$ & -5.32 & -2.90 & 3.03 & -5.22 & -2.25 & 2.96 \\
\hline $\mathrm{C}_{5}$ & -5.60 & -2.88 & 2.71 & -5.38 & -2.88 & 2.50 \\
\hline $\mathrm{C}_{6}$ & -5.49 & -2.57 & 2.92 & -5.30 & -2.47 & 2.83 \\
\hline $\mathrm{C}_{8}$ & -5.37 & -3.23 & 2.14 & -5.11 & -3.07 & 2.03 \\
\hline PCBM & -6.5 & -4.30 & 1.80 & - & - & - \\
\hline
\end{tabular}

$$
\Delta \mathrm{E}=\mathrm{E}_{\mathrm{LUMO}}-\mathrm{E}_{\mathrm{HOMO}}(\mathrm{eV})
$$

However, the results presented in table 2 suggest that the addition of electron-donating groups $\left(-\mathrm{H},-\mathrm{OCH}_{3},-\mathrm{N}\left(\mathrm{CH}_{3}\right)_{2}\right)$ to thiophene-phenyle co-oligomer destabilizes LUMO as well as HOMO levels. Also, the increase of the donor character is accompanied with an increase in the HOMO/LUMO energies added to a decrease in the HOMOLUMO energy gap. Furthermore, The HOMO energies level of $\mathrm{C}_{3}$ and $\mathrm{C}_{2}$ are $-4.40 \mathrm{eV}$ and $-4.74 \mathrm{eV}$ respectively which are the highest among all co-oligomers, indicating that donor groups in terminal thiophene-phenyl derivative have significantly improved the hole-creating properties of the compound.

On the one hand, the LUMO energies of the studied compounds are predicted in the following order: $\mathrm{C}_{3}(-1.51$ $\mathrm{eV})>\mathrm{C}_{2} \quad(-1.71 \mathrm{eV})>\mathrm{C}_{1} \quad(-1.87 \mathrm{eV})>\mathrm{C}_{6} \quad(-2.57 \mathrm{eV})>\mathrm{C}_{5} \quad(-2.65$ $\mathrm{eV})>\mathrm{C}_{4}(-2.90 \mathrm{eV})>\mathrm{C}_{8}(-3.23 \mathrm{eV})>\mathrm{C}_{7}(-3.24 \mathrm{eV})$. In fact, the LUMO energy level becomes more stabilized for cooligomers that have more character acceptor as appears in figure 3 .

The lower value of LUMO (corresponds to the largest value of the electronic affinity (AE)) reduces the injection barrier for electrons from the cathode and provides interesting transport properties. On the other hand, it is clear that the radical $(\mathrm{CN})$ cyanide enormously affects energies levels and the gap. The (HOMO-LUMO) gap of $\mathrm{C}_{7}(2.40 \mathrm{eV})$ 
and $\mathrm{C}_{8}(2.14 \mathrm{eV})$ is the narrowest among all compounds, thanks to the high acceptor character of cyanide $(\mathrm{CN})$ to the increasing of the $\pi$-electron density in the backbone related to the presence of the spacer vinyl. This ethylene spacer reduces the steric interactions between neighboring thiophenes, causing a more planar structure $[35,37]$. So, it can be said that, the para-cyanophenyl end groups together with the spacer vinyl in $\mathrm{C}_{8}$ induces the longest effective conjugation length and the smallest band gap in $\mathrm{C}_{8}$ derivatives. Thus, these compounds present an excellent charge transport proprieties along the conjugation path.

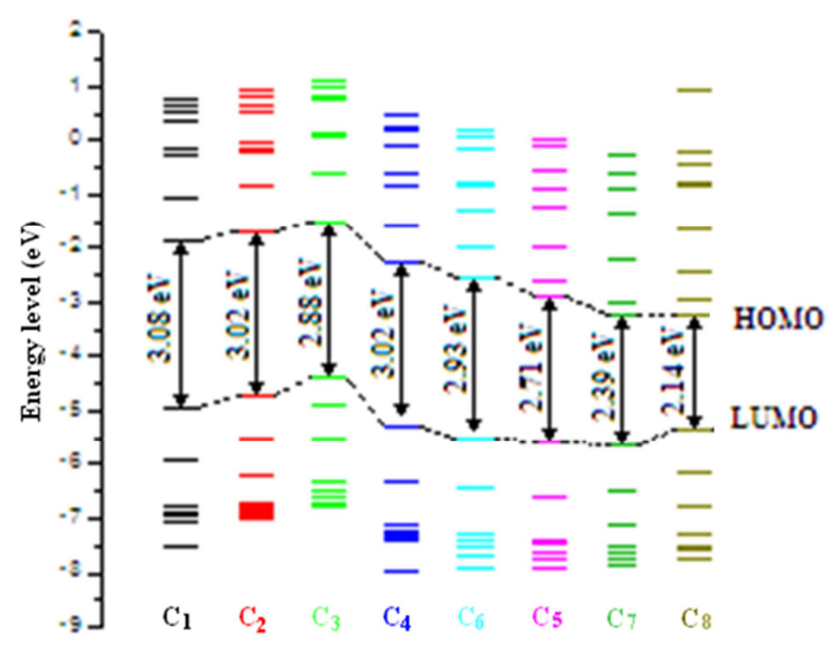

Figure 3. Electronic structure of different compounds under study.

Taking into account the solvent effect, for structures including acceptor groups, there is a destabilization of the two energy levels HOMO and LUMO and a slight decrease in gap between 0.18 and $0.05 \mathrm{eV}$. On the other hand, for structures $\mathrm{C}_{1}$, $\mathrm{C}_{2}$ and $\mathrm{C}_{3}$, we can observe a stabilization of the energy levels (HOMO and LUMO) induced by solvent effect, leading to a decrease in the gap (HOMO-LUMO). Meanwhile, we note a destabilization of the energy levels (HOMO and LUMO) of $\mathrm{C}_{4}$, $\mathrm{C}_{5}, \mathrm{C}_{6}, \mathrm{C}_{7}$ and $\mathrm{C}_{8}$ in solvent phase.

The contour plots of important frontier molecular orbitals of thiophene-phenyle co-oligomers are plotted in Figure 4.

The electron density of HOMO-n and LUMO+m for all co-oligomer is mainly concentrated in the thienyl-phenyl backbone. For HOMO orbital of $\mathrm{C}_{7}$ and $\mathrm{C}_{8}$ in ground state, we observe a high electronic density in vinyl- thiophene unit, a low electronic density localized in the para-cyano-phenyl rings. However for orbital LUMO, there is an intra molecular charge transfer toward the terminals parasubstituted phenyl, and a good distribution of the electron density at all along the aromatic ring moiety of the oligomer.
Concerning the higher excited state $(\mathrm{LUMO}+\mathrm{m})$, we note a significant migration of the electronic density from the center of the chain to the end para-substituted phenyl groups in particular for $\mathrm{C}_{8}$. This phenomenon is more observed in the case of $\mathrm{C}_{8}$, related to strong $\pi$-electron delocalization and to high conduction favored by vinyl units. It is worth noting, that for $(\mathrm{HOMO}-\mathrm{n})$ and $(\mathrm{LUMO}+\mathrm{m})$ orbital, for structures incorporating electron donating groups $\left(-\mathrm{H},-\mathrm{OCH}_{3},-\mathrm{N}\right.$ $\left.\left(\mathrm{CH}_{3}\right)_{2}\right)$, there is a high localization of the electronic density in the thiophene rings of the main chain. Whereas, for other structures incorporating acceptor substituents, an extension of the electronic density distribution toward terminal phenyl ring is observed.

\begin{tabular}{|c|c|c|c|c|}
\hline & номо-1 & номо & LUMO & LUMO+1 \\
\hline$c_{1}$ & 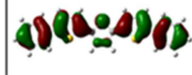 & .9090808\% & \%8\%. & $\%$ \\
\hline $\mathrm{C}_{2}$ & $60040.070 \%$ & 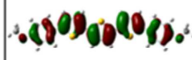 & 6 & 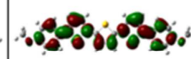 \\
\hline$c_{3}$ & 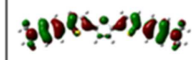 & : & 68\%89. & ๑ా \\
\hline$c_{4}$ & oldesop. & 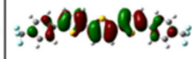 & 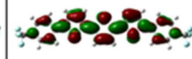 & $-80 \%$ \\
\hline$C_{5}$ & 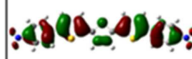 & : & $40-39$ & $80^{\circ} \%$ \\
\hline$c_{6}$ & 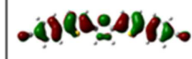 & . & - :-8:- & 0 \\
\hline 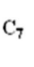 & 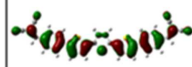 & & & \\
\hline $\mathrm{C}_{8}$ & . & 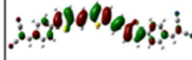 & & 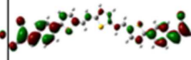 \\
\hline
\end{tabular}

Figure 4. Contour plots of the molecular orbitals (HOMO, LUMO) of different co-oligomers under study in the neutral state.

\subsection{Absorption Properties}

To gain insights into the electronic transition and excitation properties, the absorption properties are simulated using the TD/B3LYP and TD/CAM-B3LYP/6-31G (d,p) method on the optimized $\mathrm{S}_{0}$ geometries in the presence or not of the solvent at PCM model in chloroform.

The oscillator strength for $\mathrm{S}_{0} \rightarrow \mathrm{S}_{1}$ assigned to $\mathrm{HOMO} \rightarrow$ LUMO transition for all co-oligomers, leading to maximum absorption, while the transitions $(\mathrm{H} \rightarrow \mathrm{L}+1, \mathrm{H}-$ $1 \rightarrow \mathrm{L}+1)$ are obtained with weak oscillator strength. The longest wavelength of absorption spectrum $\left(\lambda_{\max }\right)$, corresponding oscillator strength (f) values, and the vertical $\mathrm{S}_{0} \rightarrow \mathrm{S}_{1}$ excitation energies are listed in Table 3 .

Table 3. Main transition states, the corresponding assignments, wavelength and oscillator strength, for all compounds, recorded with TD/B3LYP/6-31G(d,p)/ method.

\begin{tabular}{lllll}
\hline Compound & Electronic transition & Wavelength $\mathbf{~ n m} / \mathbf{E g}(\mathbf{e V})$ & Oscillator strength $(\boldsymbol{f})$ & MO/character + coefficient \\
\hline \multirow{2}{*}{$\mathrm{C}_{1}$} & $\mathrm{~S}_{0} \rightarrow \mathrm{S}_{1}$ & $442.7(2.80)$ & 1.5724 & $\mathrm{H}-0 \rightarrow \mathrm{L}+0(+100 \%)$ \\
& $\mathrm{S}_{0} \rightarrow \mathrm{S}_{2}$ & $276.8(4.48)$ & 0.1533 & $\mathrm{H}-1 \rightarrow \mathrm{L}+1(+39 \%) \mathrm{H}-2 \rightarrow \mathrm{L}+0(+7 \%)$ \\
& $\mathrm{S}_{0} \rightarrow \mathrm{S}_{3}$ & $222.5(5.57)$ & 0.0783 & $\mathrm{H}-6 \rightarrow \mathrm{L}+1(+26 \%) \mathrm{H}-1 \rightarrow \mathrm{L}+4(9 \%)$ \\
$\mathrm{C}_{2}$ & $\mathrm{~S}_{0} \rightarrow \mathrm{S}_{1}$ & $450.4(2.75)$ & 1.7305 & $\mathrm{H}-0 \rightarrow \mathrm{L}+0(+100 \%)$ \\
& $\mathrm{S}_{0} \rightarrow \mathrm{S}_{2}$ & $282.2(4.39)$ & 0.2788 & $\mathrm{H}-1 \rightarrow \mathrm{L}+1(+63 \%) \mathrm{H}-0 \rightarrow \mathrm{L}+4(+13 \%)$ \\
\hline
\end{tabular}




\begin{tabular}{|c|c|c|c|c|}
\hline Compound & Electronic transition & Wavelength $\mathrm{nm} / \mathrm{Eg}(\mathrm{eV})$ & Oscillator strength $(f)$ & MO/character + coefficient \\
\hline \multirow{5}{*}{$\mathrm{C}_{3}$} & & & & $\mathrm{H}-2 \rightarrow \mathrm{L}+0(+12 \%) \mathrm{H}-4 \rightarrow \mathrm{L}+0(+9 \%)$ \\
\hline & $\mathrm{S}_{0} \rightarrow \mathrm{S}_{3}$ & $231.8(5.36)$ & 0.0318 & $\mathrm{H}-3 \rightarrow \mathrm{L}+1(+86 \%)$ \\
\hline & $\mathrm{S}_{0} \rightarrow \mathrm{S}_{1}$ & $477.3(2.60)$ & 1.8693 & $\mathrm{H}-0 \rightarrow \mathrm{L}+0(+99 \%)$ \\
\hline & $\mathrm{S}_{0} \rightarrow \mathrm{S}_{2}$ & $294.8(4.22)$ & 0.1793 & $\mathrm{H}-0 \rightarrow \mathrm{L}+4(+66 \%) \mathrm{H}-1 \rightarrow \mathrm{L}+1(+9 \%)$ \\
\hline & $\mathrm{S}_{0} \rightarrow \mathrm{S}_{3}$ & $246.5(5.03)$ & 0.0923 & $\begin{array}{l}\mathrm{H}-0 \rightarrow \mathrm{L}+7(+32 \%) \mathrm{H}-0 \rightarrow \mathrm{L}+5(+21 \%) \\
\mathrm{H}-8 \rightarrow \mathrm{L}+0(+20 \%) \mathrm{H}-2 \rightarrow \mathrm{L}+1(+5 \%)\end{array}$ \\
\hline \multirow{3}{*}{$\mathrm{C}_{4}$} & $\mathrm{~S}_{0} \rightarrow \mathrm{S}_{1}$ & $448.5(2.76)$ & 1.6857 & $\mathrm{H}-0 \rightarrow \mathrm{L}+0(+100 \%)$ \\
\hline & $\mathrm{S}_{0} \rightarrow \mathrm{S}_{2}$ & $283.7(4.37)$ & 0.2348 & $\mathrm{H}-1 \rightarrow \mathrm{L}+1(+79 \%) \mathrm{H}-4 \rightarrow \mathrm{L}+0(+9 \%)$ \\
\hline & $\mathrm{S}_{0} \rightarrow \mathrm{S}_{3}$ & $224.2(5.53)$ & 0.0701 & $\mathrm{H}-6 \rightarrow \mathrm{L}+1(+80 \%) \mathrm{H}-1 \rightarrow \mathrm{L}+4(11 \%)$ \\
\hline \multirow{3}{*}{$\mathrm{C}_{5}$} & $\mathrm{~S}_{0} \rightarrow \mathrm{S}_{1}$ & $506.1(2.45)$ & 1.6475 & $\mathrm{H}-0 \rightarrow \mathrm{L}+0(+100 \%)$ \\
\hline & $\mathrm{S}_{0} \rightarrow \mathrm{S}_{2}$ & $330.9(3.75)$ & 0.1618 & $\mathrm{H}-1 \rightarrow \mathrm{L}+1(+78 \%)$ \\
\hline & $\mathrm{S}_{0} \rightarrow \mathrm{S}_{3}$ & $283.9(4.38)$ & 0.0744 & $\begin{array}{l}\mathrm{H}-4 \rightarrow \mathrm{L}+1(+68 \%) \mathrm{H}-0 \rightarrow \mathrm{L}+6(14 \%) \\
\mathrm{H}-3 \rightarrow \mathrm{L}+0(9 \%)\end{array}$ \\
\hline \multirow{3}{*}{$\mathrm{C}_{6}$} & $\mathrm{~S}_{0} \rightarrow \mathrm{S}_{1}$ & $468.3(2.65)$ & 1.8616 & $\mathrm{H}-0 \rightarrow \mathrm{L}+0(+100 \%)$ \\
\hline & $\mathrm{S}_{0} \rightarrow \mathrm{S}_{2}$ & $299.9(4.13)$ & 0.2375 & $\begin{array}{l}\mathrm{H}-1 \rightarrow \mathrm{L}+1(+77 \%) \mathrm{H}-0 \rightarrow \mathrm{L}+4(10 \%) \\
\mathrm{H}-4 \rightarrow \mathrm{L}+0(5 \%)\end{array}$ \\
\hline & $\mathrm{S}_{0} \rightarrow \mathrm{S}_{3}$ & $228.6(5.43)$ & 0.0592 & $\mathrm{H}-6 \rightarrow \mathrm{L}+1(+50 \%) \mathrm{H}-1 \rightarrow \mathrm{L}+4(+41 \%)$ \\
\hline \multirow{3}{*}{$\mathrm{C}_{7}$} & $\mathrm{~S}_{0} \rightarrow \mathrm{S}_{1}$ & $573.5(2.16)$ & 2.0616 & $\mathrm{H}-0 \rightarrow \mathrm{L}+0(+100 \%)$ \\
\hline & $\mathrm{S}_{0} \rightarrow \mathrm{S}_{2}$ & $400.4(3.10)$ & 0.6329 & $\mathrm{H}-0 \rightarrow \mathrm{L}+2(+71 \%) \mathrm{H}-1 \rightarrow \mathrm{L}+1(+25 \%)$ \\
\hline & $\mathrm{S}_{0} \rightarrow \mathrm{S}_{3}$ & $281.2(4.41)$ & 0.1891 & $\begin{array}{l}\mathrm{H}-5 \rightarrow \mathrm{L}+0(+28 \%) \mathrm{H}-0 \rightarrow \mathrm{L}+5(+21 \%) \\
\mathrm{H}-1 \rightarrow \mathrm{L}+2(11 \%)\end{array}$ \\
\hline \multirow{3}{*}{$\mathrm{C}_{8}$} & $\mathrm{~S}_{0} \rightarrow \mathrm{S}_{1}$ & $637.4(1.95)$ & 2.7822 & $\mathrm{H}-0 \rightarrow \mathrm{L}+0(+100 \%)$ \\
\hline & $\mathrm{S}_{0} \rightarrow \mathrm{S}_{2}$ & $456.2(2.72)$ & 0.7217 & $\mathrm{H}-0 \rightarrow \mathrm{L}+2(+80 \%) \mathrm{H}-1 \rightarrow \mathrm{L}+1(+15 \%)$ \\
\hline & $\mathrm{S}_{0} \rightarrow \mathrm{S}_{3}$ & $305.1(4.06)$ & 0.2217 & $\begin{array}{l}\mathrm{H}-3 \rightarrow \mathrm{L}+1(+33 \%) \mathrm{H}-8 \rightarrow \mathrm{L}+0(+36 \%) \\
\mathrm{H}-1 \rightarrow \mathrm{L}+3(+15 \%) \mathrm{H} \rightarrow \mathrm{L}+6(+13 \%)\end{array}$ \\
\hline
\end{tabular}

On the one hand, from the UV- vis absorption spectra, we observe the similar absorption behavior of all co-oligomers $\left(\mathrm{C}_{1}-\mathrm{C}_{8}\right)$. The vertical $\mathrm{S}_{0} \rightarrow \mathrm{S}_{1}$ excitation energies based on the TD-B3LYP gas phase calculations for the optimal B3LYP geometries are $1.95 \mathrm{eV}$ to $2.80 \mathrm{eV}$ for all thiophenephenylene derivatives. The excitation energies obtained from CAM-B3LYP functional are higher by 0.20 to $0.70 \mathrm{eV}$.
Furthermore, the inclusion of the solvent effect using the continuum model (C-PCM) leads to a red shift with respect to the gas phase calculations. On the other hand, as shown in table 4 a typical difference from 30 to $100 \mathrm{~nm}$ between the wavelengths of absorption calculated by the TD- B3LYP and TD-CAM-B3LYP method in gas or solvent phase.

Table 4. The first electronic vertical excitations were calculated using TD-B3LYP/6- 31G (d,p), TD-CAM-B3LYP/6-31G(d,p) method in gas and solvent phase and (b): Experimental absorption wavelength [3, 45].

\begin{tabular}{|c|c|c|c|c|c|c|c|}
\hline \multicolumn{5}{|c|}{ TD-B3LYP/6-31G(d,p) } & \multicolumn{3}{|c|}{ TD-CAM-B3LYP/6-31G(d,p) } \\
\hline Compound & & $\lambda_{\max }$ & $\mathbf{E}_{\text {ex }}$ & f & $\lambda_{\max }$ & $\mathbf{E}_{\mathrm{ex}}$ & f \\
\hline \multirow{2}{*}{$\mathrm{C}_{1}$} & Gas & 442.7 & 2.80 & 1.5724 & 392.5. & 3.16 & 1.5938 \\
\hline & Solvent & 468 & 2.61 & 1.742 & $413\left(406^{\mathrm{a}}\right)$ & 3.00 & 1.7361 \\
\hline \multirow{2}{*}{$\mathrm{C}_{2}$} & Gas & 450.4 & 2.75 & 1.7305 & 395.8 & 3.13 & 1.7747 \\
\hline & Solvent & 480 & 2.58 & 1.889 & $419\left(405^{\mathrm{b}}\right)$ & 2.96 & 1.8995 \\
\hline \multirow{2}{*}{$\mathrm{C}_{3}$} & Gas & 477.3 & 2.60 & 1.8693 & 410.3 & 3.02 & 2.0015 \\
\hline & Solvent & 519 & 2.39 & 2.027 & 519 & 2.39 & 2.0276 \\
\hline $\mathrm{C}_{4}$ & Solvent & 478 & 2.59 & 1.853 & 419 & 2.96 & 1.8538 \\
\hline \multirow{2}{*}{$\mathrm{C}_{5}$} & Gas & 433.7 & 2.86 & 1.4642 & 354.6 & 3.50 & 1.8941 \\
\hline & Solvent & 564 & 2.20 & 1.827 & 448 & 2.77 & 2.1809 \\
\hline \multirow{2}{*}{$\mathrm{C}_{6}$} & Gas & 468.3 & 2.65 & 1.8616 & 405.9 & 3.05 & 1.9425 \\
\hline & Solvent & 500 & 2.48 & 2.059 & 429 & 2.89 & 2.1052 \\
\hline \multirow{2}{*}{$\mathrm{C}_{7}$} & Gas & 573.5 & 2.16 & 2.0616 & 456.7 & 2.71 & 2.6257 \\
\hline & Solvent & 628 & 1.97 & 2.327 & 489 & 2.54 & 2.8339 \\
\hline
\end{tabular}

Also, the absorption power of all thiophene-phenylene derivatives increases in the solvent and a shift towards longer wavelength is observed. According to absorption spectra as shown in figure 5 and compared to $\mathrm{C}_{1}$, the $\pi-\pi^{*}$ absorption peaks of the main chains of $\mathrm{C}_{2}-\mathrm{C}_{8}$ is shifted, which should be attributed to the different electron-acceptor (donor) ability of the additional substituents groups on the end of oligomers chain.
It is interesting to note that, with the increase of the number and character of the acceptor (donor) end groups on the conjugated side chains, the absorption spectra is shifted. More importantly, the absorbance peak in the visible region increased from $\mathrm{C}_{4}$ to $\mathrm{C}_{8}$. This phenomenon indicates that for these co-oligomers the electron-acceptor substituents in their end-chains can also induce an absorption red shift, and a significant increase of the absorption intensity. 
We note that, the first vertical excitation energies collected in Table 4 using B3LYP functional are by $0.2-0.8 \mathrm{eV}$ lower than that obtained by CAM-B3LYP. The absorption spectra of co-oligomers (Figure 6) show two major absorption bands. One of them is relatively weak and situated in the near-UV region (250-400 $\mathrm{nm}$ ) corresponding to the $\pi-\pi^{*}$ electron transition.

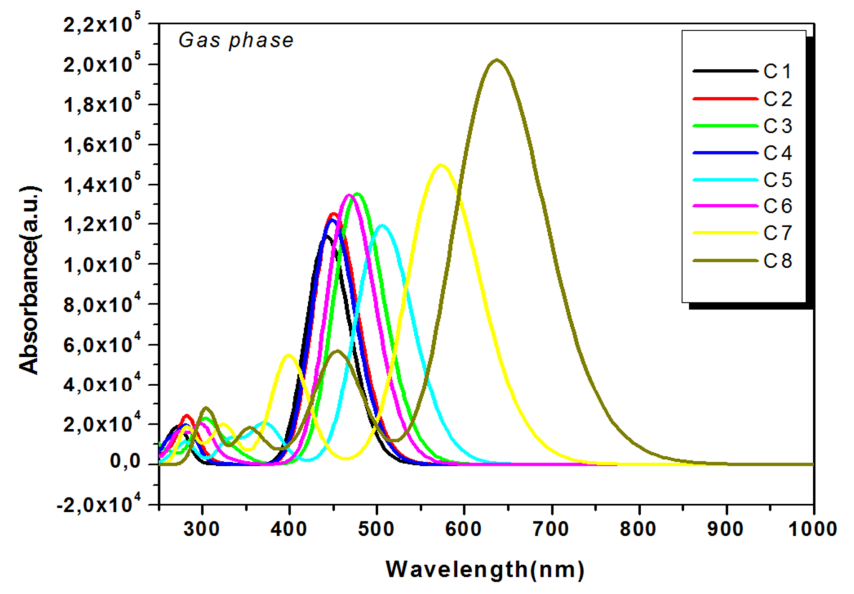

(a)

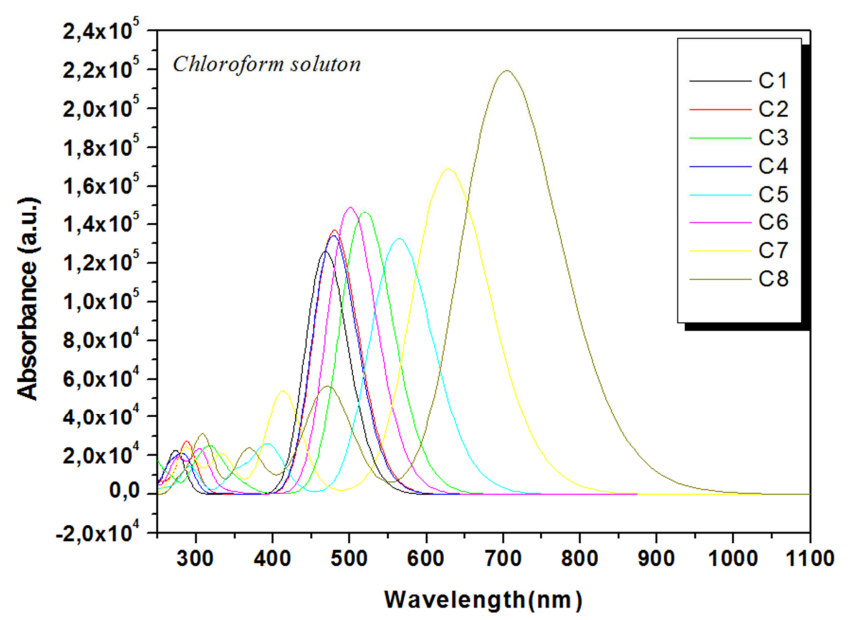

(b)

Figure 5. Absorption spectra of all co-oligomers calculated using TDB3LYP/6-31G (d,p): (a) in gas phase (b) in solution phase (chloroform).

The other one, which is a higher absorption, is located in the visible region (400-700 $\mathrm{nm}$ ) and can be assigned to an intra-molecular charge transfer (ICT) between the donor unit and the acceptor end group. Except, compound $\mathrm{C}_{8}$, which presents the absorption bands in the visible region whatever the calculation is.

It has been observed that the increase of the acceptor character leads to red shift and an increase in oscillator values. The absorption spectra depicted in figures 5 and 6 show that the simulated absorption spectra are red-shifted with insertion of $\pi$-spacer length from $C_{7}$ to $C_{8}$. Several studies show that the insertion of spacer groups could enhance the charge carrier's transfer in the polymer [38]. However, increasing the acceptor character with the increase of the number of the acceptor groups on the conjugated end chains, from $\mathrm{C}_{6}$ to $\mathrm{C}_{8}$ increase the conjugation length of molecule and the absorption spectra are shifted. This red shift of the maximum absorption band is significantly observed in solvent phase (chloroform).

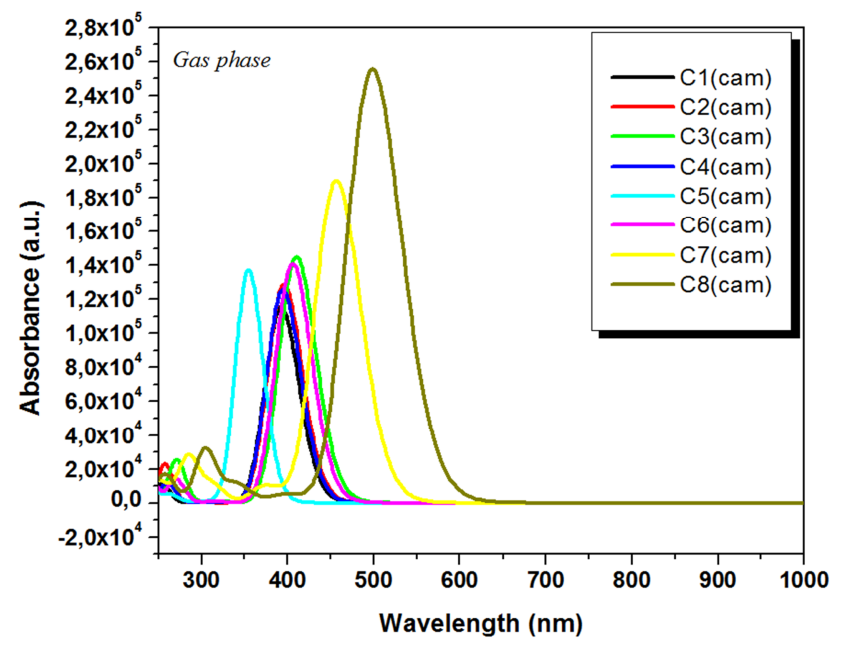

(a)

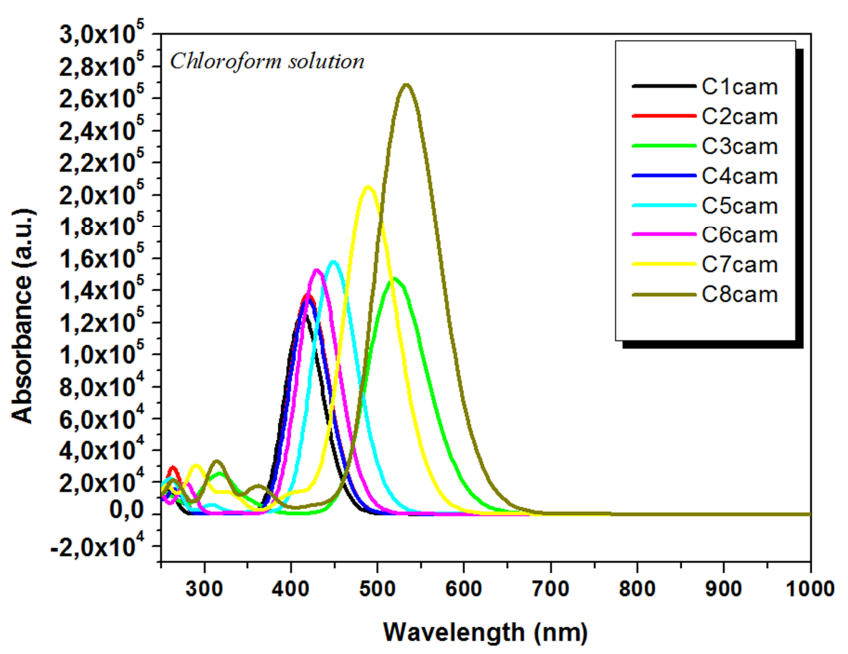

(b)

Figure 6. Absorption spectra of all co-oligomers calculated using TD-camB3LYP/6-31G (d,p): (a) in gas phase (b) in solution phase (chloroform).

These results suggest that the optical properties of the designed co-oligomers could be readily tuned by changing the acceptors substituent and the electron-donating substituent on the chain. Thus, these compounds could harvest more light at the longer-wavelength side, which is beneficial to further increase the photo-to-electric conversion efficiency of corresponding solar cell.

\subsection{Reorganization Energies}

The charge transfer process in organic material can be described using the hopping model where $M^{*}$ represents the neighboring molecule in a neutral state undergoing charge transfer, and $\mathrm{M}+$ or $\mathrm{M}-$ molecules contain either the hole or electron, respectively. 
The charge transport rate could be approximated by the

$$
M^{+/-}+M^{*} \rightarrow M+M^{*+/-}
$$

Marcus electron-transfer theory with Equation (2) [39, 40, 48-51].

$$
k_{\text {hole/electron }}=\frac{4 \pi^{2}}{h} \frac{1}{\sqrt{4 \pi \lambda_{\text {hole/electron } k_{B} T}}} V^{2} \exp \left(-\frac{\lambda_{\text {hole/electron }}}{4 K_{B} T}\right)
$$

Where $\mathrm{T}$ is the temperature, $\mathrm{h}$ the Planck constant and $\mathrm{k}_{\mathrm{B}}$ the Boltzmann constant. Both parameters of key importance in this charge transfer process are the reorganization energy $\lambda$ for hole or electron, and the intermolecular electronic transfer integral between neighboring molecules. For efficient charge transport, the reorganization energy has to be small.

$E_{0}^{+}\left(E_{0}^{-}\right)$is the energy of the cation (anion) calculated with the optimized structure of the neutral molecule. Similarly, $E_{+}^{0}$ $\left(E_{-}^{0}\right)$ is the energy of the neutral molecule calculated at the optimized cationic (anionic) state, and $E_{+}\left(E_{-}\right)$is the energy of the optimized cation (anion) structure. Finally, $E_{0}$ is the energy of the neutral molecule at ground state.

$$
\begin{gathered}
\lambda_{\text {hole }}=\left(\mathrm{E}_{0}^{+}-\mathrm{E}_{+}\right)+\left(\mathrm{E}_{+}^{0}-\mathrm{E}_{0}\right) \\
\lambda_{\text {electron }}=\left(\mathrm{E}_{0}^{-}-\mathrm{E}_{-}\right)+\left(\mathrm{E}_{-}^{0}-\mathrm{E}_{0}\right)
\end{gathered}
$$

The reorganization energy of hole $\left(\lambda_{\text {hole }}\right)$ and electron $\left(\lambda_{\text {electron }}\right)$ are calculated by DFT//B3LYP/6-31G $(\mathrm{d}, \mathrm{p})$. The $\lambda_{\mathrm{e}}$ values for molecules $\mathrm{C}_{6}$ and $\mathrm{C}_{5}$ as shown in Table $5(0.262$ and $0.269 \mathrm{eV})$ are slightly lower than that which is found for tris-(8-hydroxyquinolinato) aluminum(III) (Alq3) $\left(\lambda_{\mathrm{e}}=0.276\right.$ $\mathrm{eV})$, which is a typical electron transport material [41].

Table 5. Ionization potentials (IP), electronic affinities (EA) and reorganization energy for hole $\left(\lambda_{\text {hole }}\right)$ and electron ( $\left.\lambda_{\text {electron }}\right)$ values of different co-oligomers.

\begin{tabular}{lllllllll}
\hline Compound & IP $(\mathbf{e V})$ & $\mathbf{E A}(\mathbf{e V})$ & $\boldsymbol{\lambda}_{\mathbf{1}}(\mathrm{eV})$ & $\boldsymbol{\lambda}_{\mathbf{2}}(\mathrm{eV})$ & $\boldsymbol{\lambda}_{\mathbf{3}}(\mathrm{eV})$ & $\boldsymbol{\lambda}_{\mathbf{4}}(\mathrm{eV})$ & $\boldsymbol{\lambda}_{\mathbf{3}}+\boldsymbol{\lambda}_{\mathbf{4}}=\boldsymbol{\lambda}_{\text {electron }}$ & $\boldsymbol{\lambda}_{\mathbf{1}}+\boldsymbol{\lambda}_{\mathbf{2}}=\boldsymbol{\lambda}_{\text {hole }}$ \\
\hline $\mathrm{C}_{1}$ & 5.29 & 1.64 & 0.163 & 0.566 & 0545 & 0.201 & 0.746 \\
$\mathrm{C}_{2}$ & 5.67 & 0.76 & 0.176 & 0.198 & 0.201 & 0.160 & 0.361 \\
$\mathrm{C}_{3}$ & 5.23 & 0.61 & 1.198 & 0.157 & 0.171 & 0.209 & 0.380 \\
$\mathrm{C}_{4}$ & 6.34 & 1.40 & 0.141 & 0.174 & 0.235 & 0.005 & 0.240 \\
$\mathrm{C}_{5}$ & 6.60 & 2.03 & 0.144 & 0.125 & 0.136 & 0.165 & 0.301 \\
$\mathrm{C}_{6}$ & 6.48 & 1.71 & 0.117 & 0.145 & 0.201 & 0.141 & 0.336 \\
$\mathrm{C}_{7}$ & 6.56 & 2.44 & 0.095 & 0.106 & 0.103 & 0.097 & 0.200 \\
$\mathrm{C}_{8}$ & 6.21 & 2.50 & 0.108 & 0.108 & 0.103 & 0.105 & 0.208 \\
\hline
\end{tabular}

$$
\mathrm{IP}=(\mathrm{E})_{\text {cation }}-(\mathrm{E})_{\text {neutre }} \mathrm{EA}=(\mathrm{E})_{\text {neutre }}-(\mathrm{E})_{\text {anion }}
$$

E: stabilization energy $(\mathrm{eV})$

In addition, the $\lambda_{\mathrm{e}}$ values for the compounds $\left(\mathrm{C}_{4}, \mathrm{C}_{2}, \mathrm{C}_{7}\right.$ and $\mathrm{C}_{8}$ ) are smaller than the $\lambda_{\text {hole }}$ values, which suggests that the electron transfer rate is better than the hole transfer rate for these co-oligomers. While, the $\lambda_{\mathrm{h}}$ values for the compounds $\left(\mathrm{C}_{5}, \mathrm{C}_{1}\right.$ and $\left.\mathrm{C}_{3}\right)$ are smaller than the $\lambda_{\mathrm{e}}$ values, this reveals that the hole transport is better. Furthermore, according to table 5 , we note for $\lambda_{\text {hole }}\left(\mathrm{C}_{1}>\mathrm{C}_{2}>\mathrm{C}_{3}\right)$, which indicate that the increase in donor character leads to a decrease of $\lambda_{\text {hole }}$ values, indicating an increase in the transport property.

We note the similar values of $\lambda_{h}$ and $\lambda_{e}(0.200 \mathrm{eV})$ for compounds $\mathrm{C}_{7}$ and $\mathrm{C}_{8}$ indicating that the existence of thiophene moiety and vinyl as a bridge also four cyanide $(\mathrm{CN})$ substituents offer up a high acceptor character to the structure, which induces better electron / hole transport. Thus, the increase of conjugation in co-oligomer $\mathrm{C}_{7}$ and $\mathrm{C}_{8}$ also improves charge transport ability compared to other compounds.

The compounds having the largest dipole moments are expected to be most soluble in polar solvents, in the fundamental state. The arrangement is: $\mu\left(\mathrm{C}_{1}\right)<\mu\left(\mathrm{C}_{3}\right)<\mu$ $\left(\mathrm{C}_{8}\right)<\mu \quad\left(\mathrm{C}_{4}\right)<\mu \quad\left(\mathrm{C}_{2}\right)<\mu \quad\left(\mathrm{C}_{6}\right)<\mu \quad\left(\mathrm{C}_{5}\right)<\mu \quad\left(\mathrm{C}_{7}\right)$. Typically, structures having acceptors substituent $(\mathrm{CN}, \mathrm{NO} 2)$ have higher dipole moment values than those with electron donating substituent, $(-\mathrm{H},-\mathrm{CH} 3,-\mathrm{OCH} 3)$. With the exception of $\mathrm{C}_{8}$, the dipole moment (1.612 D) is low, due to a high conjugation and a strong delocalization of $\pi$ electrons, related to a high planarity of the structure. According to the table $6 \Delta \mu_{\text {eg }}$ for structures $C_{7}$ is the highest compared to the other compounds. Consequently, in $\mathrm{C}_{7}$ the dissociation and charge transfer in donor-acceptor interface is better.

Table 6. Dipole moment $\mu$ (Debye) of all compounds, in ground and excited state.

\begin{tabular}{llll}
\hline \multirow{2}{*}{ Compound } & \multicolumn{2}{l}{ The dipole moment $\boldsymbol{\mu}$ (Debye) } & \multirow{2}{*}{$\Delta \boldsymbol{\mu}_{\mathrm{eg}}$} \\
\cline { 2 - 3 } & Ground state & Excited state & 0.229 \\
\hline $\mathrm{C}_{1}$ & 0.502 & 0.731 & 0.503 \\
$\mathrm{C}_{2}$ & 2.363 & 2.866 & 0.520 \\
$\mathrm{C}_{3}$ & 0.664 & 0.144 & 0.369 \\
$\mathrm{C}_{4}$ & 1.752 & 2.121 & 0.509 \\
$\mathrm{C}_{5}$ & 3.011 & 3.522 & 0.459 \\
$\mathrm{C}_{6}$ & 2.847 & 3.306 & 0.860 \\
$\mathrm{C}_{7}$ & 9.907 & 10.767 & 0.531 \\
$\mathrm{C}_{8}$ & 1.612 & 2.143 & \\
\hline
\end{tabular}

\subsection{Photovoltaic Properties}

These results suggest that $\mathrm{C}_{7}, \mathrm{C}_{8}$ should be used as an active layer in solar cell device. Particularity, we are shown that $\mathrm{C}_{8}$ as a donor compound exhibit a better optoelectronic proprieties and balanced electron/hole transport (the lower $\lambda_{\mathrm{h}}$ and $\lambda_{\mathrm{e}}$ ) performance. For this reason, we select this cooligomer to be blended with the 1-(3-methoxycarbonyl) propyl-1-phenyl-[6,6]-C61 (PCBM) as an acceptor compound in an organic bulk heterojunction (BHJ) solar cell 
(Figure 7).

The Power Conversion Efficiency (PCE) of solar cell increases with the open circuit voltage parameter $\left(\mathrm{V}_{\mathrm{oc}}\right)$. Then, a low HOMO level of the donor is necessary to provide a large $\mathrm{V}_{\mathrm{oc}}$. The theoretical values of the $\mathrm{V}_{\mathrm{oc}}$ are determined from the following expression [42]: $\mathrm{V}_{\mathrm{oc}}=\mathrm{E}$ $\left|E_{H O M O}^{\text {Donor }}-E_{\text {LUMO }}^{\text {Acceptor }}\right|-0.3=0.77 \mathrm{eV}$. Donor with smaller band gaps is able to absorb more solar photons, therefore, create larger short-circuit current (Jsc). The corresponding structure of the photovoltaic devices using ITO (Indium Tin Oxide) and LiF: Al (Lithium Fluoride: Aluminum) as electrodes are schematically depicted in figure 8 .

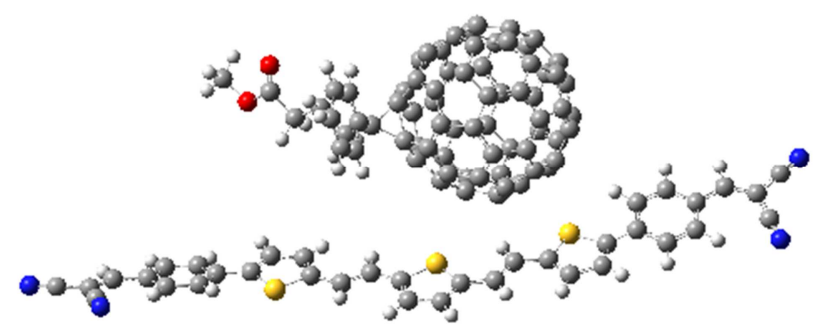

Figure 7. Optimized geometric structure of $C_{8}:$ PCBM simulated with B3LYP/6-31G $(d, p) /$ method.

Vaccum level

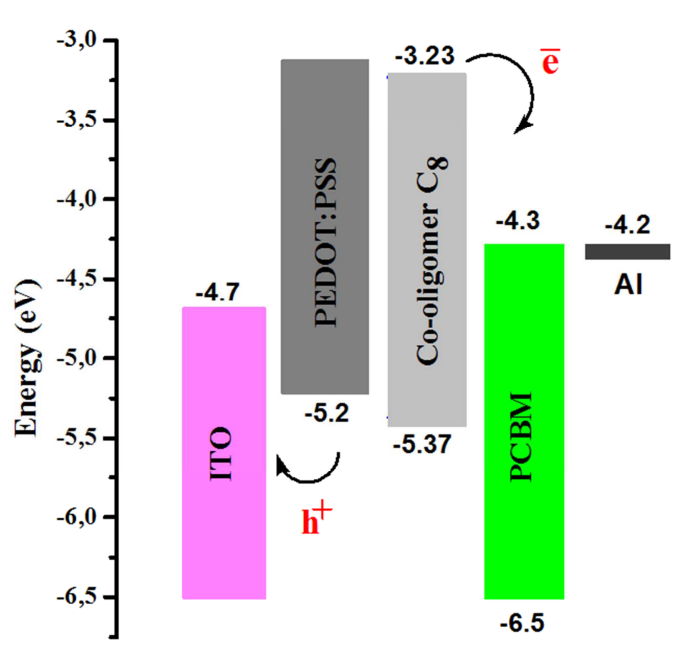

Figure 8. Energy band diagram for co-oligomer $C_{8}$ donor with a PCBM acceptor.

\section{Conclusion}

The electronic structures and optical properties of thiophene-phenylene co-oligomers have been investigated in this study. The absorption spectra are evaluated at the TD/B3LYP/6-31G (d,p) and TD/CAM-B3LYP/6-31G (d,p) level in both gas and solvent phase to study the electronic transitions of these compounds. Thiophene-phenylene cooligomers with a conjugated PTnP $(n=3)$ core and different terminal groups $\left(\mathrm{CF}_{3}, \mathrm{CN}, \mathrm{NO}_{2}, \mathrm{MeO}\right.$ and $\left.\mathrm{N}\left(\mathrm{CH}_{3}\right)_{2}\right)$ are theoretically studied. The co-oligomers $\mathrm{C}_{7}$ and $\mathrm{C}_{8}$ are the most coplanar conformation characterized by a more extended conjugated length due to the insertion of vinyl unit. This planarity leads to a bathochromic shift in the compounds' spectral response. We can conclude that introducing electron donors (such as $\mathrm{MeO}$ and $\mathrm{N}(\mathrm{CH} 3)_{2}$ ) to the main backbone significantly increases hole-injection ability but decreases electron-injection ability of the molecule. At the same time, the theoretical results show that the terminals substitutents $\left(\mathrm{CN}, \mathrm{CF}_{3}\right.$ and $\left.\mathrm{NO}_{2}\right)$ have a remarkable effect on the levels of energies of molecular orbitals as well as the electronic transitions spectra in addition to playing a dominant role in stabilizing the LUMO energy level. Moreover, the incorporation of both vinyl and acceptor end groups on the benzene ring of the main-chains is an effective way to enhance the visible absorption and improve the transport properties of the thiophene-phenylene derivatives.

The calculated results show that their electronic and optical properties are significantly affected by the electrondonating (withdrawing), also by the vinyl bridge for the compounds under investigation. Our results suggest that the co-oligomers $\mathrm{C}_{1}-\mathrm{C}_{8}$ are expected to be promising candidates for electronic organic materials.

\section{References}

[1] T. Hiramatsu, T. Shimada, S. Hotta, H. Yanagi (2008). Photoluminescence dynamics of thiophene/phenylene cooligomer thin films based on Förster energy transfer, Thin Solid Films 516, 2700-2703.

[2] T. Yamao, K. Juri, A. Kamoi, S. Hotta (2009). Field-effect transistors based on organic single crystals grown by an improved vapor phase method, Organic Electronics 10, 12411247.

[3] S. Ae Lee, S. Hotta, F. Nakanishi (2000), Spectroscopic Characteristics and Intermolecular Interactions of Thiophene/Phenylene Co-Oligomers in Solutions, J. Phys. Chem. A, 104, 1827-1833.

[4] Q. Lia, Y. Duana, H. Z. Gaob, Z. M. Sua, Y. Genga (2015) Theoretical investigations into the electronic structures and electron transport properties of fluorine and carbonyl endfunctionalized quarter thiophenes, J. Mol. Graphics and Modell. 59, 50-58.

[5] A. Hlel, A. Mabrouk, M. Chemek, I. Ben Khalifa, K. Alimi (2015). A DFT study of charge-transfer and opto-electronic properties of some new materials involving carbazole units. Computational Condensed Matter 3, 30-40.

[6] S. Hotta, T. Yamao (2011). The thiophene/phenylene cooligomers: exotic molecular semiconductors integrating highperformance electronic and optical functionalities, J. Mater. Chem. 21, 1295-1304.

[7] S. Kanazawa, A. Uchida, M. Ichikawa, T. Koyama, Y. Taniguchi (2008). Photoluminescence and Optical Gain Properties of a Crystalline Thiophene/Phenylene Co-oligomer, Jpn. J. Appl. Phys. 47, 8961-8964.

[8] P. Lère-Porte, J. J. E. Moreau, C. Torreilles, F. Serein-Spirau, A. Righi, J. L. Sauvajol, M. Brunet (2000). Synthesis, orientation and optical properties of thiophenedialkoxyphenylene copolymers, J. Mater. Chem. 10, 927-932. 
[9] A. Azazi, A. Mabrouk, M. Chemek, D. Kreher, K. Alimi (2014). DFT modeling of conjugated copolymers photophysical properties: Towards organic solar cell application, Synthetic Metals 198, 314-322.

[10] G. Sang, E. Zhou, Y. Huang, Y. Zou, G. Zhao, Y. Li (2009). Incorporation of Thienylene vinylene and Triphenylamine Moieties into Polythiophene Side Chains for All-Polymer Photovoltaic Applications, J. Phys. Chem. C 113, 5879-5885.

[11] F. C. Grozema, L. P. Candeias, M. Swart, P. Th. van Duijnen, J. Wildeman, G. Hadziioanou, L. D. A. Siebbeles, J. M. Warman (2002). Theoretical and experimental studies of the optoelectronic properties of positively charged oligo (phenylene vinylene) s: Effects of chain length and alkoxy substitution, J. Chem. Phys. 117, 11366-11378.

[12] A. Irfan, A. G. Al-Sehemi (2014). DFT study of the electronic and charge transfer properties of perfluoroarene-thiophene oligomers, Journal of Saudi Chemical Society 18, 574-580.

[13] Vinod D. Gupta, Abhinav B. Tathe, Vikas S. Padalkar, Prashant G. Umape, Nagaiyan Sekar (2013). Red emitting solid state fluorescent triphenylamine dyes: Synthesis, photophysical property and DFT study, Dyes and Pigments 97, 429439 .

[14] X.M.Hong, H. E. Katz, A. J. Lovinger, Bo-Cheng Wang, K. Raghavachari (2001), Thiophene-Phenylene and ThiopheneThiazole Oligomeric Semiconductors with High Field-Effect Transistor On/Off Ratios, Chem. Mater.13, 4686-4691.

[15] D. Shohei1, O.Yasuyuki1, S. Fumio, H. Shu, Y. Hisao (2016). Organic Light-Emitting Diodes with Heterojunction of Thiophene/Phenylene Co-Oligomer Derivatives, Journal of Nanoscience and Nanotechnology, 16, 3194-3199.

[16] S. Ayachi, S. Ghomrasni, M. Bouachrine, M. Hamidi, K. Alimi (2013). Structure-property relationships of soluble poly (2,5-dibutoxyethoxy-1,4-phenylene-alt-2,5-thienylene) $(\mathrm{PBuPT})$ for organic-optoelectronic devices, Journal of Molecular Structure 1036, 7-18.

[17] C. R. Newman, C. D. Frisbie, D. A. S. Filho, J. L- Brédas, P. C. Ewbank, K. R. Mann (2004) Chem. Mater. 16, 4436- 4447.

[18] C. R. Newman, C. D. Frisbie, F. D. A. da Silva, J. L. Bredas, P C. Ewbank, K. R. Mann (2004). Introduction to Organic Thin Film Transistors and Design of n-Channel Organic Semiconductors, Chem. Mater., 16, 4436-4451.

[19] L. Yang, J. K. Feng, Y. Liao, A. M. Ren (2007). Theoretical studies on the electronic and optical properties of two blueemitting fluorene-pyridine-based copolymers, Opt. Mat. 29, 642-650.

[20] M. Frisch, G. Trucks, H. Schlegel, G. Scuseria, M. Robb, J. Cheeseman, J. Montgomery Jr., T. Vreven, K. Kudin, J. Burant Gaussian 03, Rev. C. 02, Gaussian Inc., Pittsburgh, PA, 200.

[21] P. Hohenberg, W. Kohn (1964). Featured in Physics, Inhomogeneous Electron Gas Phys. Rev. Lett. 136, 864-871.

[22] W. Kohn, L. J. Sham (1965). Self-Consistent Equations Including Exchange and Correlation Effects, Phys. Rev. Lett. $140,1133-1138$.

[23] G. A. Petersson, A. Bennett, T. G. Tensfeldt, M. A. Al-Laham, W. A. Shirley, J. Mantzaris (1988). A complete basis set model chemistry. I. The total energies of closedshell atoms and hydrides of the first-row atoms, J. Chem. Phys. 89, 2193-2218.
[24] A. D. Becke (1993). Density-functional thermochemistry. III. The role of exact exchange, J. Chem. Phys. 98, 5648-5652.

[25] B. Miehlich, A. Savin, H. Stoll, H. Preuss (1989). Results obtained with the correlation energy density functionals of becke and Lee, Yang and Parr, Chemical Physics Letters 157, 200-206.

[26] C. Lee, W. Yang, R. G. Parr (1988). Development of the Colle-Salvetti correlation-energy formula into a functional of the electron density, Physical Review B 37, 785-789.

[27] T. Yanai, D. Tew, N. Handy (2004). A new hybrid exchangecorrelation functional using the Coulomb-attenuating method (CAM-B3LYP), Chem. Phys. Lett. 393, 51-57.

[28] M. E. Casida, in: D. P. Chong (Ed.), Recent Advances in Density Functional Methods, Part I, World Scientific, Singapore, 1995, pp. 155-193.

[29] E. Gross, J. Dobson, M. Petersilka (1996). Density functional theory of time-dependent phenomena, Top. Curr. Chem. 181, $81-72$.

[30] S. Miertus, E. Scrocco, J. Tomasi (1981). Electrostatic interaction of a solute with a continuum. A direct utilizaion of $\mathrm{AB}$ initio molecular potentials for the prevision of solvent effects, J. Chem. Phys. 55, 117-129.

[31] S. Miertus, J. Tomasi (1982). Approximate evaluations of the electrostatic free energy and internal energy changes in solution processes, J. Chem. Phys. 65, 239-245.

[32] J. B. Foresman, M. Head-Gordon, J. A. Pople, M. J. Frisch (1992). Toward a systematic molecular orbital theory for excited states, J. Phys. Chem., 96, 135-149.

[33] S. I. Gorelsky, SWizard Program, University of Ottawa, Ottawa, Canada, 2009. http://www.sg-chem.net/.

[34] S. I. Gorelsky, A. B. P. Lever (2001). Electronic structure and spectra of ruthenium diimine complexes by density functional theory and INDO/S. Comparison of the two methods, J. Organometal. Chem. 635, 187-196.

[35] J. C. Earles, K. C. Gordon, D. L. Officer, P. Wagner (2007). A Spectroscopic and Computational Study of the Neutral and Radical Cation Species of Conjugated Aryl-Substituted 2,5Bis (2-thien-2-ylethenyl) thiophene-Based Oligomers, J. Phys. Chem. A 111, 7171-7180.

[36] P. Wagner, A. M. Ballantyne, K. W. Jolley, D. L. Officer (2006). Synthesis and characterization of novel styryl-substituted oligothienylenevinylenes, Tetrahedron 62, 2190-2199.

[37] S. Ghomrasni, S. Ayachi, K. Alimi (2015). New acceptordonor-acceptor (A-D-A) type copolymers for efficient organic photovoltaic devices, Journal of Physics and Chemistry of Solids 76, 105-111.

[38] J. Zhang, H. B. Li, Y. Geng, S. Z. Wen, R. L. Zhong, Y. Wu, Q. Fu, Z. M. Su (2013). Modification on C219 by coumarin donor toward efficient sensitizer for dye sensitized solar cells: A theoretical study, Dyes Pigm. 99, 127-135.

[39] R. A. Marcus (1956). On the Theory of Oxidation-Reduction Reactions Involving Electron Transfer. J. Chem. Phys. 24, 966-978.

[40] R. A. Marcus (1993). Theory and experiment, Rev. Mod. Phys. $65,599-610$. 
[41] B. C. Lin, C. P. Cheng, Z. Q. You, C. P. Hsu (2005). Charge transport properties of tris (8-hydroxyquinolinato) aluminum (III): why it is an electron transporter. J. Am. Chem. Soc., 127, 66-67.

[42] G. D. Sharma, P. Bala Raju, M. S. Roy (2008). Effect of functional groups of acceptor material on photovoltaic response of bulk hetero-junction organic devices based on tin phthalocyanine (SnPc), Sol. Energ. Mat. Sol. Cells 92, 261272 .

[43] R. Hirase, M. Ishihara, T. Katagiri, Y. Tanaka, H. Yanagi, S. Hotta (2014). Alkyl mono substituted thiophene/phenylene cooligomers: Synthesis, thin film preparation, and transistor device characteristics, Organic Electronics 15, 1481-1492.

[44] M. Turbiez, P. Frère, M. Allain, C. Videlot, J. Ackermann, J. Roncali (2005). Design of Organic Semiconductors: Tuning the Electronic Properties of $\pi$-Conjugated Oligothiophenes with the 3,4-Ethylenedioxythiophene (EDOT) Building Block, Chem. Eur. J. 11, 3742-3752.

[45] O. H. Omar, F. Babudri, G. M. Farinola, F. Naso, A. Operamolla, A. Pedone (2011) Synthesis of d-glucose and 1- phenylalanine substituted phenylene-thiophene oligomers, Tetrahedron 67, 486-494.

[46] S. Kanazawa, M. Ichikawa, T. Koyama, Y. Taniguchi (2006). Self-Waveguided Photoemission and Lasing of Organic Crystalline Wires Obtained by an Improved Expitaxial Growth Method, Chem. Phys. Chem 7. 1881-1884.

[47] G. A. Petersson, M. A. Al-Laham (1991). A complete basis set model chemistry. II. Open-shell systems and the total energies of the first-row atoms, J. Chem. Phys. 94. 6081-6090.

[48] R. A. Marcus (1965). On the Theory of Electron-Transfer Reactions. VI. Unified Treatment for Homogeneous and Electrode Reactions, J. Chem. Phys. 43, 679-701.

[49] M. D. Newton, N. Sutin (1984). Electron Transfer Reactions in Condensed Phases, Annual Rev. Phys. Chem. 35, 437-480.

[50] R. A. Marcus, N. Sutin (1985). Electron transfers in chemistry and biology, Biochim. Biophys. Acta 811, 265-322.

[51] P. F. Barbara, T. J. Meyer, M. A. Ratner (1996). Contemporary Issues in Electron Transfer Research, J. Phys. Chem. 100, 13148-13168. 